\title{
Diagnostics and treatment of prolonged menstrual bleedings in girls with von Willebrand disease
}

\author{
Paweł Łaguna ${ }^{1}$ (D) Andrzej Mital $^{2}$ (D) \\ ${ }^{1}$ Department of Pediatric Oncology, Hematology and Transplantology Medical University of Warsaw \\ ${ }^{2}$ Department of Haematology and Transplantology, Medical University of Gdańsk
}

\begin{abstract}
Summary
Von Willebrand disease (VWD) is the most common inherited bleeding disorder which often remains undiagnosed despite pronounced symptoms such as recurrent nose and gum bleeds, easy bruising and prolonged menstrual bleedings [1,2]. Acute anemia related to blood loss and iron deficiency is one of the most common consequences of VWD.

In this paper we present cases of teenager and adult women who suffered from prolonged bleeds despite antifibrinolytic agents and hormonal treatment. This led to acute anemia which required multiple transfusions of red blood cell concentrate. The observed symptoms prompted extended diagnostics which led to VWD. Following implementation of periodic prophylaxis with VWF/FVIII concentrate the symptoms were alleviated.
\end{abstract}

\section{Key words: von Willebrand disease, VWD, prolonged menses, bleeding prophylaxis}

\section{Introduction}

Von Willebrand disease (VWD) is the most common congenital bleeding disorder with an incidence rate of $0.6-1.3 \%$ in the general population. The symptomatic form occurs less frequently, i.e. in about $0.01 \%$ of the population [3-5]. The cause of VWD is a genetically determined autosomal dominant or recessive inherited quantitative or qualitative deficiency of plasma von Willebrand factor (VWF). This plasma protein produced by endothelial cells and megakaryocytes is composed of various size multimers of approximately 12 hour half-life (9-15 h). The symptoms of VWD are associated with impaired primary haemostasis (platelet adhesion to the endothelium) as well as secondary haemostasis (reduced factor VIII activity in plasma).
There are 3 major types of VWD: Type 1, Type 2 , and Type 3 .

- Type 1 - mild form (occurs in approx. $75 \%$ of patients) associated with moderate quantitative VWF deficiency: lower ristocetin cofactor activity (VWF:RCo) relative to VWF antigen level (VWF: Ag) and VWF-GPIb interactions.

- Type 2- moderate form (occurs in 20-25\% of patients). A qualitative defect with no change in plasma VWF levels but characterized by structural and functional defects of VWF . it is further sub-divided into four types (2A, $2 \mathrm{~B}$, $2 \mathrm{M}$, and $2 \mathrm{~N}$ ) that differ with regard to the type of VWF dysfunction.

- 2A - characterized by a decreased VWF mediated platelet adhesion due to structural VWF deficiency;

Correspondence address: prof. dr hab. n. med Paweł Łaguna, Department of Pediatric Oncology, Hematology and Transplantology Medical University of Warsaw, 63a Żwirki i Wigury St., 02-091 Warszawa, phone/fax 223179621 , e-mail:plaguna@wum.edu.pl

Translation: mgr Krystyna Dudziak 
- 2B - characterized by pathologically increased VWF — platelet affinity/interactions;

- $2 \mathrm{~N}$ - characterized by a marked decline in the binding affinity for factor VIII (reduced binding of VWF to factor VIII);

- $2 \mathrm{M}$ - characterized by a decline in the binding affinity for platelets (reduced binding of VWF to platelets).

- Type 3 - the rarest and the most severe form. It is caused by recessive mutation which leads to undetectable VWF levels and low levels of factor VIII.

The most common laboratory screening assays for VWD are:

- Closure time (PFA 100/200 - Platelet Function Analyzer);

- VWF antigen level (vWF:Ag);

- VWF ristocetin cofactor activity (vWF: RCo);

- VWF collagen binding test (vWF:CB);

- activated partial thromboplastin time (APTT);

- factor VIII coagulant activity (FVIII:C);

- increasingly common are assays that directly evaluate VWF-GPIb interactions (VWF binding to the GPIb receptor on platelets).

Specific assays of VWF function are required to clarify the type of VWD in order to facilitate optimal treatment of affected patients. To differentiate between type 1 and type 2 VWD it is helpful to assess VWF: RCo/vWF: Ag or VWF: CB/vWF: Ag ratio. Typically, a ratio $<0.7$ is indicative of VWD type 2. It is also advisable to perform analysis of vWF multimeters. Confirmatory testing for type $2 \mathrm{~B}$ involves low-dose ristocetin-induced platelet aggregation tests (LD-RIPA) and genetic tests. VWF: Factor VIII binding activity test is required if type $2 \mathrm{~N}$ is suspected [1-5].

Currently, there are two recommended options to guide VWD therapy and prophylaxis:

- desmopressin (DDAVP; 1-desamino-8-D-arginine vasopressin);

- VWF concentrates, if DDAVP is contraindicated, ineffective or treatment must be extended/continued [7].

Replacement therapy relies on concentrates of both factor VIII and VWF which differ with regard to VWF: RCo/FVIII ratio and content of high-molecular-weight VWF multimeters. Most effective are concentrates with VWF: RCo/FVIII ratio of $>1$. For many years now Haemate $\mathrm{P}$ has been considered a gold standard in the treatment of VWD. It is a plasma-derived concentrate with the 2.4 ratio of von Willebrand factor (vWF:RCo) to factor VIII and the high-molecular-weight multimer content comparable to that in human plasma [1].
Haemate $\mathrm{P}$ has been used with high efficacy and safety in management of bleeding, preparation for surgery as well as in perimenstrual prophylaxis.

The paper presents three teenager VWD cases ( $2 \times$ type 2 and $1 \times$ type 3 ) as well as 2 cases of adult women suffering from prolonged bleeds despite antifibrinolytic and hormonal treatment. They required multiple red blood cell ( $\mathrm{RBC}$ ) transfusions and iron supplementation due to acute anemia.

All three teenagers were on a 2-3 day prophylaxis with Haemate $\mathrm{P}$ administered during menstruation which led to marked reduction of bleeding frequency and stabilization of hemoglobin $(\mathrm{Hb})$ levels. No supplementary RBC transfusions were required.

\section{Case 1}

A 14.5-year old with VWD and no family history of bleeding disorders. First bruising symptoms occurred at 9 months. At the age of 3 she suffered from tongue laceration/injury accompanied by difficult-to-control severe bleeding. The results of platelet and plasma tests (APTT, INR) were within normal. At 13, she experienced heavy menstrual bleeding. Coagulation tests (APTT, INR, fibrinogen) were normal. Multiple RBC transfusions were performed due to recurrent acute anemization $(\mathrm{Hb}$ 5-6 g\%). Hormonal treatment proved ineffective so extended diagnostics towards VWD was launched. Type 2 VWD was recognized (factor VIII level 51\%, vWF: RCo $14.5 \%$, vWF: Ag - 18.3\%). After discontinuation of hormonal therapy, prophylactic Haemate $\mathrm{P}$ treatment was introduced at a dose of $40 \mathrm{IU} / \mathrm{kg}$ body weight during the first 3 period days.

As result, menstruation became normal and prolonged massive bleeds leading to anemization and multiple RBC transfusions were prevented.

\section{Case 2}

A 14-year-old with heavy periods observed during 6 months prior to hospitalization. Hormonal treatment proved ineffective and diagnostics led to VWD type 2; laboratory tests (factor VIII 61.50\%, VWF: RCo 20.80\%, VWF: Ag - 36.30\%). Prophylactic Haemate P treatment was introduced during the first 2 days of the period. Menstruation became normal.

\section{Case 3}

A 16-year-old diagnosed with VWD type 3 in the first year of life. Positive family history for VWD type 3 (brother and sister). The first symptoms (easy bruising) were observed in the 7th 
month. Following frequent episodes of epistaxis and two joint bleeds to the right ankle, VW/FVIII concentrate treatment on demand was introduced. Since the first menstruation, there were reports of prolonged bleeding and acute anemizatio. Coagulation tests revealed: factor VIII activity $-4.8 \%$, VWF: $\mathrm{RCo}<3.0 \%$, VWF: $\mathrm{Ag}<10 \%$.

Haemate $P$ prophylactic treatment was introduced on 1st day of each period and continued for the next 3 menstruation days at a dose of $40 \mathrm{IU} / \mathrm{kg}$ body weight. Menstrual bleeding became normal.

\section{Case 4}

A 18-year-old woman with symptoms of a bleeding disorder since childhood (easy bruising, prolonged bleeds following injury or tooth extraction). Negative family history of bleeding disorders. Since 14, profuse menstruation bleeds, menorrhagia leading to acute iron-deficiency anemia (hemoglobin level ca $6 \mathrm{~g} / \mathrm{dl}$ ). Antifibrinolytic agents and etamsylate were ineffective as was oral iron supplementation. Moreover, the patient was diagnosed with celiac disease and irritable bowel syndrome (IBS). Parenteral iron therapy was poorly tolerated, and she required antihistamine and glucocorticosteroid premedication. Laboratory diagnostics for bleeding disorders was not initiated until the age of 16 . Tests revealed APTT up to $45 \mathrm{~s}$, occlusion time (PFA 100), col/epi up to $200 \mathrm{~s}$, col/ADP up to $198 \mathrm{~s}$. Diagnostics for VWD followed (vWF: RCo - 15\%, vWF: Ag - 24\%, VIII - 42\%, the vWF: RCo/vWF: Ag index was 0.6). VWD type 2 was confirmed. The subtype was not determined as VWF multimeter analysis could not be performed. The DDAVP trial (Minirin $0.3 \mu \mathrm{g} /$ $/ \mathrm{kg}$ iv) proved exceptionally positive and resulted in a $>200 \%$ increase in VWF activity and VWF antigen as well as normalization of occlusion time in the PFA-100 apparatus. Unfortunately, the response to desmopressin was unsatisfactory and the patient manifested tachycardia, skin redness, and water retention. DDAVP was not recommended/ /indicated. Despite poor tolerance, the patient still required parenteral iron therapy. At 17 , prophylactic treatment with intravenous Haemate $\mathrm{P}$ at dose of $40 \mathrm{IU} / \mathrm{kg}$ bw. was administered from the 1 st to the last menstruation day (4 days on average). The effect proved satisfactory; menstrual bleeding became normal. Tranexamic acid and etamsylate were discontinued. Currently, blood parameters are nor$\mathrm{mal}(\mathrm{Hgb} 13.1 \mathrm{~g} / \mathrm{dl}, \mathrm{MCV} 86 \mathrm{fl})$, the patient however requires intravenous administration of $200 \mathrm{mg}$ of iron every 4 months due to comorbidities, The prophylactic treatment markedly improved the patient's comfort of life.

\section{Case 5}

A 19-year-old woman with symptoms of easy bruising and heavy menstrual bleeding. Since the first period, she required multiple RBC transfusions but no assays to diagnose bleeding disorder had ever been performed. At 17, she was admitted to the Hematology Department of the Medical University of Gdańsk. Decreased factor VIII activity (15\%), prolonged closure time $>300 \mathrm{~s}$ (PFA-100 analyzer), vWF: Ag - 87\%, APTT 54 s were determined. No inhibitor was detected. vWF:Factor VIII binding test was negative. VWD type $2 \mathrm{~N}$ was diagnosed. A DDAVP trial was performed and normalization of clotting parameters occurred. Blood count parameters were within normal range. No $\mathrm{RBC}$ transfusions or iron supplementation/substitution were required. Perimenstrual prophylaxis with VWF/FVIII concentrate (Haemate P) was recommended due to intolerance to desmopressin.

\section{Discussion}

The origins of prophylactic treatment for patients with congenital coagulation disorders date back to 1958, when prof. I.M. Nilsson et al. launched prophylaxis with coagulation factor concentrates in severe hemophilia patients at the Malmö University Hospital [6]. In the years that followed, the doses of coagulation factor were increased, and the intervals between successive administrations were modified for better treatment outcome [5]. The next step proposed by P. Petrini was administration of factor VIII concentrates to 1 and 2-year-old children with hemophilia. The experience of Swedish hemophilia centers served as basis for development of guidelines for prophylactic treatment of children aged 1-2 years with the aim of keeping factor VIII and IX activity at the level $>1 \%$. Evidence-based guidelines were issued in 1994 by MASAC (Medical and Scientific Advisory Council) and National Hemophilia Foundation. Drawing from the experience with hemophilia patients, a prophylactic treatment program for VWD patients was launched at the Malmö University Hospital and Karolinska University Hospital in Stockholm.

The inclusion criteria for the study were: VWF ristocetin cofactor activity (VWF: $\mathrm{RCo})<8 \%$ and factor FVIII activity (FVIII: C) $<10 \%$. The age of patients ranged from 3-65 years [7]. 
Most adult patients were on prophylactic treatment for a minimum of 10 years, and 18 children were prophylactically treated for more than 5 years. The study group consisted of: 28 patients with VWD type 3 , 4 patients with type $2 \mathrm{~B}, 2$ with type $2 \mathrm{~A}$ and 1 with type 1 .

The mean age of patients $<18$ eligible for prophylaxis was $4(2-13)$. For 17 adult patients $(>15)$ the mean age at the start of prophylaxis was 27 (3-57). The main indications for prophylactic therapy were: epitaxis/oral bleeding, gastrointestinal (GI) bleeding, bleeding in joints and menorrhagia. Prophylaxis for younger patients was usually indicated due to mucocutaneous bleeding; for older patients, after bleeding into joints and arthropathy. Until the mid-1980s, substitution therapy for patients with coagulation disorders was based on antihemophilic plasma fraction C-I which is of higher yield and purity than cryoprecipitate. During administration of fraction C-I blood group matching did not apply. Since then, VWF/FVIII concentrates (Haemate P) have been in use for VWD prophylaxis.

Doses of the medicinal product ranged from $12-50 \mathrm{IU} . / \mathrm{kg}$ bw (24 IU/kg on average) administered intravenously 1-3 times a week for several years.

The study demonstrated that long-term prophylactic treatment is indicated for most patients with VWD type 3 and type 2 depending on the clinical context. Early start of prophylactic treatment (at the age of 5), may prevent arthritis and encourage/promote normal growth. The significance of VWD prophylaxis for heavy and frequent bleeding episodes has also been confirmed by 2021 recommendations of ISTH (International Society on Thrombosis and Haemostasis) and WFH (World Federation of Hemophilia) [8].
The above cases are presented to draw attention to such common VWD symptoms as heavy menstrual bleeding and recurrent nosebleeds which occur both in teenagers and adult women. Prophylactic treatment with VWF/FVIII concentrates (Haemate $\mathrm{P}$ ) significantly reduces bleeding frequency and contributes to stabilization of hemoglobin concentration. There is no need for supplementary RBC transfusions and the patient's quality of life is much improved.

\section{References}

1. Mital A. Haemate P - zastosowanie w profilaktyce i leczeniu krwawień w chorobie von Willebranda oraz indukcji immunotolerancji w hemofilii A powikłanej inhibitorem. Acta Haematol Pol. 2017; 48(2): 125-129, doi: 10.1016/j.achaem.2017.05.002.

2. Zdziarska J, Chojnowski K, Klukowska A, et al. Postępowanie w chorobie von Willebranda. Zalecenia Polskiego Towarzystwa Hematologów i Transfuzjologów 2008. Med Prakt (wyd. spec.). 2008: 12 .

3. James PD, Connell NT, Ameer B, et al. 2021 guidelines on the diagnosis of von Willebrand disease. Blood Adv. 2021; 5(1): 280-300.

4. Ragni MV, Machin N, Malec LM, et al. Von Willebrand factor for menorrhagia: a survey and literature review. Haemophilia. 2016; 22(3): 397-402, doi: 10.1111/hae.12898, indexed in Pubmed: 26843404.

5. Elbatarny M, Mollah S, Grabell J, et al. Normal range of bleeding scores for the ISTH-BAT: adult and pediatric data from the merging project. Haemophilia. 2014; 20(6): 831-835, doi: 10.1111/ hae.12503, indexed in Pubmed: 25196510.

6. Nilsson IM, Blomback M, Blomback B. v. Willebrand's disease in Sweden; its pathogenesis and treatment. Acta Med Scand. 1959; 164: 263-278, indexed in Pubmed: 14427267.

7. Berntorp E, Petrini P. Long-term prophylaxis in von Willebrand disease. Blood Coagul Fibrinolysis. 2005; 16 (Suppl. 1): S23-S26, doi: 10.1097/01.mbc.0000167659.23262.18, indexed in Pubmed: 15849523.

8. Connell NT, Flood VH, Brignardello-Petersen R, et al. ASH ISTH NHF WFH 2021 guidelines on the management of von Willebrand disease. Blood Adv. 2021; 5(1): 301-325, doi: 10.1182/ bloodadvances.2020003264, indexed in Pubmed: 33570647. 